\title{
Ampliação da Jornada Escolar e o Terceiro Setor: a atuação do CENPEC
}

\author{
Regis Eduardo Coelho Argüelles da Costa' \\ 'Universidade Federal Fluminense (UFF), Niterói/RJ - Brasil
}

RESUMO - Ampliação da Jornada Escolar e o Terceiro Setor: a atuação do CENPEC. O artigo analisa a elaboração e a divulgação de propostas para a ampliação da jornada escolar pelo Centro de Estudos e Pesquisas em Educação, Cultura e Ação Comunitária (CENPEC), de 1993 a 2006. Buscamos nos apropriar das proposições e das estratégias de convencimento utilizadas junto às sociedades civil e política, a partir de diversos documentos assinados pela ONG e seus intelectuais. A seguir, avaliamos a assimilação desse conjunto de proposições pelo Programa Mais Educação, política de ampliação de jornada do governo federal, de 2007.

Palavras-chave: Jornada Escolar. Terceiro Setor. Política Educacional.

ABSTRACT - Extension of the School Day and the Third Sector: the role of CENPEC. The article analyzes the development and dissemination of proposals for expand the school day by the Centro de Estudos e Pesquisas em Educação, Cultura e Ação Comunitária (CENPEC) from 1993 to 2006. We seek to the propositions, and persuasion strategies used along the civil and politic society, from various documents signed by the NGO and its intellectuals. Next, we evaluate the assimilation of this set of propositions by Programa Mais Educação, school day expansion policy of the Federal Government, since 2007.

Keywords: School Day. Third Sector. Educational Policy.

Educação \& Realidade, Porto Alegre, v. 43, n. 2, p. 401-414, abr./jun. 2018. 401 http://dx.doi.org/10.1590/2175-623660756 


\section{Introdução}

Nos últimos 20 anos, certas organizações da sociedade civil foram fundamentais na articulação da agenda da responsabilidade social empresarial para a educação. Esse trabalho analisa a elaboração, a divulgação e a assimilação de uma proposta de ampliação da jornada pelo Centro de Estudos e Pesquisas em Educação, Cultura e Ação Comunitária (CENPEC), uma organização não governamental (ONG) paulista ligada ao Banco Itaú Unibanco. Tendo por recorte os anos de 1993 a 2006, faremos uso de variada documentação assinada pela instituição e por seus intelectuais, buscando destacar os eixos teórico-metodológicos da proposta e as suas principais estratégias de divulgação.

Em sociedades democráticas de massa, cujo padrão de acumulação capitalista é acompanhado da garantia universal de direitos políticos, a dominação política de classe deve considerar, para além das estruturas coercitivas, o momento da hegemonia social ou do consenso. A manutenção do poder pelas classes dirigentes demanda, portanto, a organização e a divulgação de proposições econômicas, políticas e culturais para o conjunto da sociedade, através de seus intelectuais, organizados em aparelhos privados de hegemonia. Tais proposições, todavia, não miram apenas nos interesses estritos de determinada fração de classe, alerta Gramsci (2000b, p. 41-42). Segundo ele,

[...] esta é a fase mais estritamente política, que assinala a passagem nítida da estrutura para a esfera das superestruturas complexas; é a fase em que as ideologias geradas anteriormente se transformam em 'partido', entram em confrontação e lutam até que uma delas, ou pelo menos uma combinação delas, tenda a prevalecer, a se impor, a se irradiar por toda a área social, determinando, além da unicidade dos fins econômicos e políticos, também a unidade intelectual e moral, pondo todas as questões em torno das quais ferve a luta não no plano corporativo, mas no plano 'universal', criando assim a hegemonia de um grupo social fundamental sobre uma série de grupos subordinados.

As políticas públicas para a educação são compreendidas neste trabalho como os resultados instáveis de uma complexa correlação de forças, que envolve o Estado em sentido estrito e a sociedade civil (Gramsci, 2000a). Os diversos estágios das políticas públicas - da elaboração à avaliação - implicam operações complexas de hegemonia (Buttigieg, 2003). Buscamos aqui mapear as principais estratégias nesse sentido no âmbito do Estado ampliado, conforme as necessidades de manutenção ou de alargamento da base social de dominação.

Políticas recentes têm estimulado a ampliação da jornada escolar de alunos das escolas públicas de ensino fundamental, visando à melhoria no rendimento escolar e a oferta de oportunidades socioculturais para crianças e jovens pobres. Já encontramos na Lei de Diretrizes e Bases da Educação, LDB, no 9.394, (Brasil, 1996) a determinação do aumento progressivo do tempo de permanência do aluno na escola (art. 
34), e da conjugação de esforços para que as redes escolares urbanas tenham um regime de escolas de tempo integral (art. 87, $\$ 5^{\circ}$ ). Quanto ao financiamento, o Fundo de Desenvolvimento da Educação Básica e Valorização dos Profissionais da Educação (FUNDEB), em vigor desde 2007 com a Lei no 11.494 (Brasil, 2007), garante recursos adicionais para matrículas em tempo integral ${ }^{1}$. Ainda no ano de 2007 foi lançado o Programa Mais Educação (PME), que visa ampliar os tempos, os espaços e as oportunidades de aprendizagem de crianças e adolescentes de escolas em situação de vulnerabilidade.

Concomitante aos decretos, à previsão de recursos e ao lançamento de programas especiais, duas dinâmicas destacam-se no terreno da política social que, em certa medida, estão interligadas: de um lado, a ação organizada de vários aparelhos privados associados ao empresariado visando influenciar mais diretamente as propostas governamentais e disputar os recursos públicos, cujo substrato é a agenda da responsabilidade social empresarial (Martins, 2009); de outro, a reforma do modelo de gestão pública, que ofereceu espaços para privatização da ação social, ampliando a participação do terceiro setor ${ }^{2}$ em programas que antes se desenrolavam exclusivamente no âmbito do Estado (Peroni; Adrião, 2005; Montaño, 2008).

O estudo é atravessado por inquietações concernentes às novas configurações político-ideológicas dominantes no âmbito da sociedade civil, as quais interferem no tratamento da questão educacional e, mais especificamente, nas concepções e políticas contemporâneas de ampliação da jornada para a escola brasileira. Quais organizações da sociedade civil influenciam os debates contemporâneos sobre a educação integral, e sobre a escola de tempo integral? De que maneira suas propostas são divulgadas e assimiladas pelas políticas públicas? Como essas proposições buscam equacionar alguns dos pontos nevrálgicos das políticas de jornada ampliada para o ensino fundamental, dentre os quais destacamos o papel da escola na sociedade e a adequação tanto do trabalho docente quanto dos tempos e espaços escolares?

O texto está dividido em cinco partes, a contar desta introdução. Na seguinte, sublinharemos alguns projetos coordenados pelo CENPEC nos anos de 1990, que permitem caracterizar seu modelo de atuação na educação pública. Em Formação e Proteção Integrais, Dentro e Fora da Escola, voltaremos nossa atenção para uma agenda específica de ampliação de jornada divulgada pelo CENPEC, já na década de 2000. A seção posterior cuida da assimilação dessas propostas, bem como de indicadores de resistência a elas, expressos na legislação que instituiu o Programa Mais Educação. Por último, faremos algumas considerações finais, buscando sintetizar as discussões desenvolvidas ao longo do trabalho.

\section{Tecendo Redes na Sociedade Civil e Política: os anos de 1990}

O CENPEC se identifica como uma organização da sociedade civil que, desde 1987, procura atuar no campo da educação pública. Sua primeira ação educacional em escala nacional foi o Projeto Raízes e Asas, 
Ampliação da Jornada Escolar e o Terceiro Setor

que se deu entre 1993 e 1998, contando com o apoio do Ministério da Educação (MEC) e do Banco Itaú ${ }^{3}$. O material de divulgação do projeto, distribuído por escolas de todo país em fascículos, chamava atenção para a baixa qualidade do ensino público e, em contrapartida, sugeria estratégias de intervenção no âmbito da gestão escolar, da avaliação, do ensino-aprendizagem e do trabalho docente, tendo como objetivo a melhoria dos serviços educacionais. Outra tarefa concernente ao projeto foi o registro e a análise de experiências bem-sucedidas de projetos pedagógicos implantados em 16 escolas públicas brasileiras (Souza e Silva et al, 1995).

Em muitas das estratégias do Projeto Raízes e Asas encontramos premissas caras à concepção de educação privilegiada pela ONG, como o estímulo à maior participação da comunidade na gestão da escola, a constatação de que a escola possui limitações no enfrentamento de questões sociais contemporâneas e a associação da presença de um projeto pedagógico à melhoria dos resultados dos alunos. Escrito em linguagem acessível, os nove fascículos, de cerca de 40 páginas cada, mesclam reflexões acerca de temas geradores - por exemplo, Gestão, compromisso de todos; A sala de Aula; Como Ensinar; A Escola e sua Formação Social - com relatos das experiências coletadas pelo trabalho de campo.

Em 1994, foi publicado pelo CENPEC o Guia de Ações Complementares à Escola para Crianças e Adolescentes, difundindo ações complementares à escola desenvolvidas por diferentes organizações sociais. A importância desse guia está justamente na divulgação de projetos educativos que foram concebidos e executados fora do espaço escolar sob coordenação dos educadores sociais ${ }^{4}$, profissional que ocupa posição chave nas propostas de jornada ampliada das organizações da sociedade civil ligadas ao empresariado, conforme veremos mais adiante. A tarefa de organizar essa publicação sugere que, nove anos após a sua fundação, o CENPEC já era um polo importante na aproximação do chamado terceiro setor à educação pública, aglutinando ao seu redor diversas instituições que possuíam esse foco de ação.

A posição de destaque no âmbito da sociedade civil atingiu outro nível com a criação do Prêmio Itaú-Unicef. Com uma edição a cada dois anos desde 1995, o prêmio é parte integrante do Programa Educação \& Participação, uma iniciativa da Fundação Itaú Social e do Unicef ${ }^{5}$, sendo coordenado pelo CENPEC. Destina-se a conhecer e dar visibilidade às práticas de investimento em educação fora do sistema escolar, realizadas por organizações da sociedade civil ${ }^{6}$, com o objetivo declarado de incluir aquelas práticas na agenda das políticas públicas. A organização do Prêmio Itaú-Unicef divulgou ter alcançado mais de 3.729 ONGs até o ano de 2007, dando a entender que o evento foi um dos principais responsáveis pelo enorme crescimento de organizações sociais que ofertam programas para crianças e adolescentes (Cenpec, 2008). Em outro lugar (Cenpec, 2013), a premiação é creditada como fundamental para o reaparecimento das pautas da educação integral e da ampliação de jornada no debate sobre a educação pública. 
O cenário acima foi parte de uma ampla investida de setores do empresariado nacional, no sentido de difundir os ideais da responsabilidade social empresarial, cuja implementação e desenvolvimento compõem algumas das ações estratégicas oferecidas pelo CENPEC às empresas. Dois dos organismos fundamentais nessa investida foram o Grupo de Institutos, Fundações e Empresas (GIFE) e o Instituto Ethos de Empresas e Responsabilidade Social. Fundado em 1995, o GIFE visa coordenar a atuação das empresas na questão social e no desenvolvimento da cidadania participativa. Já o Instituto Ethos, de 1998, reúne diversas empresas de diferentes tamanhos e setores da economia brasileira, com a finalidade de ampliar e estimular uma nova conduta empresarial na sociedade (Martins, 2009) ${ }^{7}$.

Algumas características de ações que se enquadram no espectro da responsabilidade social empresarial - focalização em comunidades carentes, valorização de projetos socioeducativos fora da escola e destaque ao papel dos educadores sociais na execução desses projetos - foram incorporadas a agenda da educação em jornada ampliada, na década seguinte. A tentativa de avaliar o papel do CENPEC na divulgação dessas e de outras propostas, bem como a penetração delas nas políticas públicas de ampliação de jornada serão os temas a seguir.

\section{Formação e Proteção Integrais, Dentro e Fora da Escola}

Vimos que o CENPEC, ao longo dos anos de 1990, investiu na coordenação de projetos educacionais em parceria com os setores público e privado, caracterizando-se como um dos principais articuladores de um movimento que envolveu empresas e organizações sociais interessadas em educação. Na década seguinte, a ONG voltou-se para a agenda da ampliação do tempo e das oportunidades de aprendizagem, que em 2007 tornou-se política federal para o ensino fundamental, denominada Programa Mais Educação.

Parte dessa agenda já havia sido sugerida pelo Banco Mundial (1997) para o Brasil. Reafirmando que o seu principal foco na área social se encontrava em medidas de alívio da pobreza, o Banco garantiu assistência ao governo brasileiro no desenvolvimento de políticas que propiciassem mais tempo e qualidade de ensino aos mais pobres, incluindo aí maiores oportunidades de aprendizagem. Ainda segundo a instituição, esses objetivos exigiriam definição mais clara das responsabilidades de cada ente federado, maior participação do setor privado e da sociedade civil na educação e a melhoria da gestão escolar.

A primeira ação do CENPEC que tangenciou a questão da ampliação da jornada escolar foi a publicação Educação Integral - Guia de Referência (2000). Tendo como recorte o ano de $1990 \mathrm{em}$ diante, tratou-se de pesquisa bibliográfica no acervo de três universidades paulistas (PUC-SP, UNICAMP e USP). O texto final apresenta resumos de livros, teses, dissertações e artigos relacionados a alguma concepção de educação integral. Essa pesquisa teve o intuito de subsidiar as discussões do Seminário Educação Integral - articulação de projetos e espaços de aprendizagem, parte de uma série de eventos do Projeto Educação Integral, do 
Ampliação da Jornada Escolar e o Terceiro Setor

qual a ONG fazia parte. Outro objetivo da publicação, mais ambicioso, consistia em apoiar o "[...] início de uma reflexão sobre o marco teórico-metodológico e conceitual sobre a concepção de 'educação integral”' (Cenpec, 2000, p.7).

Apesar da uma ampliação das temáticas utilizadas na pesquisa bibliográfica, a análise que acompanhou o Guia de Referência chamou atenção para a reduzida quantidade de resumos incluídos na publicação, interpretada pelos autores como sinal do pouco interesse que a comunidade acadêmica dispensava ao problema. Os trabalhos compilados indicaram uma variedade considerável de abordagens teórico-metodológicas quando o assunto é a educação integral, o que é atestado pela literatura crítica sobre o tema (Coelho, 2009). Dentre essas abordagens, o Guia destaca aquelas que dialogam com "[...] a ideia de um currículo baseado nas vivências e experiências e numa ação pedagógica organizada por projetos ou temas geradores" à medida que suas metodologias integram a "vida prática comunitária" (Coelho, 2009, p. 4-5); sublinha também projetos cujas atividades se passam em diversos ambientes de aprendizagem localizados fora da escola e que têm por foco o desenvolvimento da autonomia do estudante.

Em contraste, concepções de educação integral vinculadas à implantação de escolas de dia inteiro são criticadas pelo seu histórico de descontinuidades e pelas polêmicas que despertaram a respeito do arco de responsabilidades da escola. Por último, são valorizados novos desenhos de políticas públicas, através dos quais as organizações da sociedade civil funcionariam como mediadoras sociais e, a partir do respeito à diversidade e às diferenças, estariam franqueadas a atuar entre o Estado e as "microesferas da sociedade" (Coelho, 2009, p.6), na condução das políticas públicas.

Após a fase de diálogo e tomada de posição em relação ao estado da arte das concepções e práticas, as preocupações se voltaram para a difusão da problemática junto ao poder público, empresariado e organizações da sociedade civil e, ainda, para a indução de políticas públicas de educação integral em tempo integral. De acordo com Gramsci (2000a, p. 205), esse conjunto de estratégias segue o princípio metodológico da repetição, que é uma das mais importantes iniciativas de elaboração do consenso nas sociedades de massas.

Nesse sentido, a edição de 2003 do Prêmio Itaú-Unicef promoveu mudanças significativas no sistema de premiação e em sua estrutura organizacional. A partir dessa etapa, o critério de inscrição restringiu-se aos "[...] programas socioeducativos desenvolvidos por ONGs e desenvolvidos no contraturno escolar" (Cenpec, 2008, p.21), alterando o nome da categoria de premiação de Ações Complementares à Escola para Ações Socioeducativas. No tocante à seleção de propostas, transferiu-se o foco da escola para o "sujeito em desenvolvimento" (Cenpec, 2008), que determina que a escola compartilhe suas funções com outros atores sociais. De acordo com Cavaliere (2009), tal abordagem substitui a escola de tempo integral - tal qual eram os CIEPs, por exemplo - pelo aluno em tempo integral, que divide seu dia entre a escola e outros espaços, nos quais são oferecidas atividades diversas.

406 Educação \& Realidade, Porto Alegre, v. 43, n. 2, p. 401-414, abr./jun. 2018. 
Em relação à estrutura da premiação, sublinhamos a participação de outras instituições na condução do prêmio ${ }^{8}$ e a descentralização do processo de seleção e premiação, que permitiu o envolvimento de profissionais de secretarias municipais de educação e de "conselheiros municipais de política social" na avaliação dos projetos inscritos (Cenpec, 2009, p. 23). Para uma maior visibilidade foi firmada parceria com o Canal Futura, das Organizações Globo, que ficou responsável pela produção de conteúdo cobrindo as diversas etapas do evento.

A duradoura aliança Unicef, Itaú e CENPEC também reservou para 2003 o lançamento da coletânea de textos intitulada Muitos Lugares para Aprender, na qual foi apresentada uma concepção mais acabada das propostas da ONG para políticas de ampliação de jornada escolar. O texto de Guará (2003) - Educação, Proteção Social e muitos Espaços para Aprender-incluído na coletânea nos oferece um resumo bastante elucidativo dessa tal concepção, do qual tentaremos destacar os principais aspectos adiante ${ }^{9}$.

Considerando que o tempo dedicado à educação dos jovens está muito aquém dos desafios da contemporaneidade, a autora marca duas linhas de ação para as políticas sociais, respaldadas nos marcos da LDB e do Estatuto da Criança e do Adolescente (ECA): melhorar a educação através de uma formação integral de qualidade e fortalecer as ações de inclusão pela "proteção especial aos que dela necessitam” (Guará, 2003, p. 34). Para que tais objetivos sejam efetivamente alcançados, faz-se necessária uma conjugação de esforços que envolva o Estado, as empresas e as organizações da sociedade civil.

Ao prosseguir em seu raciocínio, Guará qualifica a escola como espaço possuidor de especificidade dentro do processo educativo, chamando atenção, entretanto, para o fato de que "nenhuma instituição pode ou consegue hoje, isoladamente, responder por toda a formação da criança e do adolescente" (Guará, 2003, p. 39). As ONGs reúnem, por sua vez, características tais como a "flexibilidade e a liberdade curricular” (Guará, 2003, p. 40), além da proximidade com a comunidade. Essas características permitem a elas associar o conhecimento escolar às demandas da vida prática com maior facilidade que as escolas, dada a rigidez curricular presente nestas últimas. Além disso, o fortalecimento da legitimidade social das ONGs pode contribuir na mobilização da comunidade em torno dos assuntos educacionais.

A conjugação da educação escolar com os projetos socioeducativos desenvolvidos pelo poder público e pelas ONGs tem por resultado, segundo a autora, uma política pública que combina educação e proteção. Essa é marca de uma concepção de educação integral voltada especialmente para aqueles em "situação social vulnerável” (Guará, 2003, p. 37), campo de ação no qual as ONGs possuem larga experiência, muitas vezes fazendo uso de trabalho voluntário.

Fundamental no arranjo descrito acima, o papel do Estado é, todavia, redefinido. Ele deve ser capaz de garantir a articulação entre as diversas políticas públicas voltadas para a infância e a adolescência, além de estimular parcerias com as organizações da sociedade civil. Reproduz-se aí o conceito de Estado-Rede, modelo cujo fim é estabele-

Educação \& Realidade, Porto Alegre, v. 43, n. 2, p. 401-414, abr./jun. 2018. 407 
Ampliação da Jornada Escolar e o Terceiro Setor

cer mecanismos de coordenação entre os múltiplos níveis institucionais em que se desenvolvem as ações dos agentes políticos (Castells, 1999).

\section{As Políticas Contemporâneas de Ampliação de Jornada e a Agenda Empresarial Para a Educação}

O desenrolar recente de ações visando ampliar a jornada escolar e as oportunidades de aprendizagem de crianças e jovens foi sensivelmente impactado pelo Programa Escola Integrada e pelo Programa Bairro-Escola, ambos de 2006 e coordenados pelas prefeituras de Belo Horizonte e de Nova Iguaçu (RJ) respectivamente. A própria política federal, o Programa Mais Educação, explicitou sua dívida para com essas duas iniciativas (Brasil, 2009).

No ano anterior ao lançamento dos programas municipais destacados no parágrafo anterior, foi lançada a revista Cadernos CENPEC. Suas duas primeiras edições expressaram uma significativa síntese da agenda da ONG para a ampliação da jornada escolar. A ideia de cidade educadora, por exemplo, é articulada à concepção de que a educação está para além da rede escolar, pois abarca "proteção social, arte, esportes e cidadania” (Cenpec, 2005, p.15). Para que se efetive tal integração, as políticas educativas devem envolver toda a cidade, incluindo aí as "[...] relações de proximidade, geradas pela família e organizações comunitárias do microterritório" (Carvalho, 2005, p. 51). Formam-se, assim, as comunidades/territórios de aprendizagem, capazes de "compartilhar saberes e construir ações em redes" (Carvalho, 2005, p. 9) ${ }^{10}$.

No número seguinte dos Cadernos CENPEC, reafirma-se que o tempo integral não pode ficar sob responsabilidade exclusiva da escola, devendo ser compartilhado com os programas socioeducativos desenvolvidos pelas ONGs. Essa ação conjunta unindo escolas e ONGs é a resposta adequada a uma sociedade cada vez mais complexa e multifacetada. De acordo com Guará (2006), o protagonismo das ONGs permite ainda que se leve em conta as múltiplas demandas do sujeito, dado o caráter comunitário desse tipo de instituição. As parcerias entre esfera pública e privada são, portanto, fundamentais para que se ofereça educação integral associada à formação integral, dotada de sensibilidade para com o local, em oposição às políticas centradas nos aparatos estatais.

Uma oferta de educação nesses moldes exige um projeto norteador, prossegue a autora, responsável pela integração de saberes acadêmicos e locais. Esses projetos devem contemplar as camadas mais vulneráveis da população - pessoas em situação de pobreza ou risco social -, conjugando educação com proteção social. A seguir, a autora chama a atenção para o fato de os educadores sociais poderem arejar o ensino ministrado na rede escolar tradicional, dada a sua vivência em centros comunitários e núcleos socioeducativos (Guará, 2006, p. 23).

Todo esse debate estava em sintonia com a agenda da responsabilidade social empresarial, que ganhou força a partir do governo de Fernando Henrique Cardoso (1995-2002). O governo do Partido dos 
Trabalhadores (PT), que o sucedeu, já vinha mostrando aproximação a certos setores do empresariado em anos anteriores, afastando-se de suas bases originárias. Saviani (2007) viu no Plano de Desenvolvimento da Educação (PDE), Decreto no 6.094 (Brasil, 2007), um dos principais expoentes da relação orgânica entre o PT e a classe empresarial. Para a elaboração do PDE foram privilegiadas as interlocuções com a referida parcela da sociedade civil, o que pode ser atestado pelo próprio texto do programa, que afirma assumir integralmente a agenda do movimento Compromisso Todos pela Educação, do qual, inclusive, o CENPEC é integrante ${ }^{11}$.

O PDE agregou mais de 30 ações direcionadas aos diferentes níveis e modalidades da educação brasileira. Um dos destaques para o ensino fundamental foi o Programa Mais Educação, que tem por objetivo oferecer formação integral aos alunos a partir de atividades no contraturno escolar. A oferta destinava-se, preferencialmente, àqueles alunos em situação de vulnerabilidade social, de escolas com baixo desempenho no Îndice de Desenvolvimento da Educação Básica (Ideb), que é o instrumento avaliativo da educação básica, consagrado pelo PDE e com índices iguais ou superiores a $50 \%$ de estudantes pertencentes a famílias participantes do Programa Bolsa Família. Além dessas premissas, o PME atendeu a cidades com população igual ou superior a 18.844 mil habitantes ${ }^{12}$.

O horizonte da formação integral expresso nas Portarias Interministeriais que instituíram o Programa Mais Educação (PI no 17/2007 e PI no 19/2007) foi bastante receptivo à participação das ONGs e ao estímulo de parcerias com o setor privado, visando à ampliação das ações do Programa. As ações socioeducativas indicadas para o contraturno escolar não se limitaram ao currículo mínimo do ensino fundamental, contemplando os campos das artes, cultura, esporte e lazer; elas podem acontecer em espaços não escolares, e seus objetivos vão da melhoria do desempenho educacional - leia-se Ideb - à "proteção social", agregando "compartilhamento comunitário" em uma "dinâmica de redes" (PI 17/2007, art. 10). Tais ações, as oficinas, são ministradas por profissionais denominados oficineiros, que podem ser alunos de licenciatura ou um educador social. Esses profissionais têm vínculo de voluntários ${ }^{13}$ e recebem uma ajuda de custo mensal para a realização das ações no contraturno, que cobrem os gastos de deslocamento à escola.

É importante ressalvar que a receptividade à agenda difundida pelo CENPEC nos anos anteriores - projetos desenvolvidos e executados por ONGs, financiados pelo poder público, mas que acontecem fora do espaço escolar e são direcionados aos mais pobres - não significou exatamente que a proposta de ampliação da jornada desenhada no PME tenha colocado a escola pública em um plano secundário. As portarias se voltam igualmente para os aspectos formais da escolarização, tais como a já citada preocupação com o reforço escolar e com a infraestrutura para a prática de esportes existente nas escolas (PI 19/2007, art. $1^{\circ}$ e 2º). A PI 19/2007 embasa suas medidas pela necessidade de ampliação do período de permanência na escola, conforme determina o artigo 34 da LDB/1996. Ademais, as oficinas devem estar em consonância com o 
Ampliação da Jornada Escolar e o Terceiro Setor

projeto político-pedagógico da unidade escolar, o que reserva uma série de responsabilidades que esta deve assumir ao implantar o Programa Mais Educação ${ }^{14}$.

Outro aspecto a ser considerado está no alcance da estratégia de ampliação de espaços educativos, estejam eles localizados na própria escola ou fora dela. As periferias das regiões metropolitanas que, de acordo com o escopo definido pelas PIs, seriam as principais áreas beneficiadas pela ampliação da jornada escolar, normalmente dispõem das escolas mais precárias em termos de infraestrutura e espaço construído. Ali também é onde há uma maior escassez de equipamentos públicos e privados - adequados para o desenvolvimento de qualquer ação pedagógica. De acordo com Cavaliere (2010), um cenário desse tipo pode levar à precarização do contraturno, tornando-o mais do mesmo no dia-a-dia do aluno.

\section{Considerações Finais}

Observamos algumas evidências do crescimento da mobilização empresarial em torno de questões educacionais, que teve como um dos principais atores o CENPEC. O discurso da ONG, desde cedo, sintonizou-se às ambições crescentes de ação social por parte do empresariado. Além disso, a ONG estruturou um amplo leque de conexões na sociedade civil e política, aliado às coordenações de projetos nacionais de pesquisa e gestão pedagógica. Para uma organização que reconstrói sua memória ressaltando a austeridade e o idealismo presentes sua fundação, os anos de 1990 marcaram o início de uma trajetória meteórica no campo da educação ${ }^{15}$

As concepções de ampliação da jornada do CENPEC, sistematicamente elaboradas a partir de 2000, pautaram-se pela defesa de uma maior participação das ONGs e dos educadores sociais na educação pública, através de parcerias público-privadas e pela gestão descentralizada das políticas. $\mathrm{O}$ foco da educação integral voltou-se para o sujeito - um sujeito de direitos -, assegurando proteção social às crianças e jovens, direito que teria valor equivalente ao da instrução formal. Recomendou-se atenção aos alunos em situação de vulnerabilidade que, para completarem sua formação, precisariam de maior assistência educacional e social. Estes seriam atendidos por voluntários, preferencialmente em espaços fora da escola.

O Programa Mais Educação foi deveras receptivo a tal agenda, o que é sugerido pela participação de setores da sociedade civil associados ao empresariado na elaboração PDE e pelas portarias que inauguraram o programa. Todavia, chama-nos atenção a preocupação do Programa com a melhoria de rendimento dos alunos e com o resguardo de algumas funções no âmbito da escola. São pistas de que, longe de reduzir a participação estatal, o programa se integra ao modelo de Estado gestor na garantia dos direitos sociais (Carvalho, 2009). Tal concepção de Estado relaciona-se, sem dúvida, à transposição de estratégias empresariais de gestão no trato da coisa pública, o que rebatem na qualidade e na seletividade classista dos serviços públicos. Resta-nos saber as diversas

410 Educação \& Realidade, Porto Alegre, v. 43, n. 2, p. 401-414, abr./jun. 2018. 
formas de resistência e consenso, engendradas no seio das instituições públicas de educação, diante dessa transformação significativa das relações entre o público e o privado na garantia do direito à educação.

Recebido em 10 de dezembro de 2015 Aprovado em 29 de maio de 2017

\section{Notas}

1 Ver, especialmente, $o$ art. $10^{\circ}$ da Lei do FUNDEB (no 11.494/2007). De acordo com o Decreto $n^{\circ} 6.253 / 2007$, art. $4^{\circ}$, a definição de tempo integral caracteriza uma jornada escolar igual ou superior a sete horas diárias. Menezes (2009), considera jornadas acima de quatro horas diárias como tempo ampliado. Ainda que tempo integral/ampliado não seja sinônimo de educação integral - pensada enquanto ação educacional que envolve diversas e abrangentes dimensões da formação dos indivíduos (Cavaliere, 2010) -, partimos da premissa de que qualquer proposta de educação integral implica em mais tempo de escola, dadas as funções ampliadas que são exercidas por ela.

2 De acordo com Garcia (2004), o terceiro setor seria composto pelas organizações sociais que não fazem parte do conjunto de instituições do Estado e do mercado. Assim, instituições sem fins lucrativos, tais quais ONGs, movimentos sociais, instituições religiosas, são exemplos de instituições do terceiro setor. A existência de um terceiro setor, que funcionaria como algo equivalente à sociedade civil é diametralmente oposta ao pensamento gramsciano. O marxista sardo postula as superestruturas dividas, para fins de análise, em dois planos: a sociedade política (momento da coerção) e a sociedade civil (momento do consenso). A inserção do mercado enquanto plano apartado da sociedade civile da sociedade política parece fundamentar-se na noção da mão invisível do primeiro, a qual aproxima as ações humanas de troca de mercadorias e dinheiro às forças da natureza. Todavia, nada mais estranho ao materialismo histórico-dialético que a ideia de um mercado apartado das forças políticas e ideológicas dominantes, ou seja, dos conflitos constituintes da sociedade civil. Para uma discussão apropriada da questão, ver Marx e Engels (1989).

3 Todo o material referente ao Projeto Raízes e Asas encontra-se disponível em <http:// www.cenpec.org.br/biblioteca/educacao/producoes-cenpec/>.Acessoem:18mar.2015.

4 Gohn (2010) afirma que os educadores sociais são os tradutores socioculturais daqueles que estão à margem da sociedade. O projeto que norteia sua atuação de tradução pressupõe um trabalho de cogestão democrática junto à comunidade que será atendida, evitando que o educador seja aquele que fala pelo outro. O objetivo maior é a promoção da cidadania (ver p. 50 e ss.).

5 O Fundo das Nações Unidas para a Infância - Unicef - foi criado no dia 11 de dezembro de 1946, por decisão unânime da Assembleia Geral das Nações Unidas. Os primeiros programas do Unicef forneceram assistência emergencial a milhões de crianças no período pós-guerra na Europa, no Oriente Médio e na China. No Brasil, o Unicef está presente desde os anos de 1995. Fonte: <http://www.unicef.org.br/>. Acesso em: 18 mar. 2015.

6 Ver <http://educacaoeparticipacao.org.br/premio-itau-unicef/>. Acesso em: 18 de mar. 2015.

7 Ainda que o escopo de ação tanto do GIFE quanto do Instituto Ethos seja mais amplo que o do CENPEC, há uma clara afinidade de objetivos entre eles como, por exemplo, o fortalecimento das organizações da sociedade civil, especialmente no 
Terceiro Setor, e a parceria com as comunidades. Ademais, a fundadora do CENPEC e o próprio Itaú são associados do GIFE.

8 Por exemplo, a União Nacional de Dirigentes Municipais de Educação (UNDIME) e o Colegiado Nacional de Gestores Municipais de Assistência Social (Congemas).

9 Isa Maria F. Rosa Guará é pedagoga, doutora em Serviço Social (PUC/SP) e pós-graduada em Psicopedagogia. Ocupa a assessoria de coordenação do CENPEC ejá foi vice-presidente da FundaçãoABRINQ pelos Direitos da Criança e do Adolescente. Assina alguns dos principais textos do grupo na defesa de uma educação integral que incorpore o direito à proteção social e a atuação das ONGs.

10 A expressão cidade educadora ganhou destaque após o lançamento, em 1990, da Carta das Cidades Educadoras, na cidade de Barcelona. O compromisso firmado nesse documento exprimiu o desejo das cidades signatárias de explorarem suas possibilidades educadoras, formais e não formais, na medida em que ambas possibilidades concorrem igualmente para a formação de um cidadão responsável.

11 O Compromisso Todos pela Educação foi um movimento lançado em setembro de 2006 em São Paulo. Identificando-se como uma iniciativa da sociedade civil, o movimento conta com representantes importantes empresas ou fundações a elas ligadas, como o Grupo Pão de Açúcar, Fundação Itaú Social, Fundação Roberto Marinho, Instituto Ayrton Senna, Instituto Itaú Cultural, entre outros (Saviani, 2007). O CENPEC também integra a rede.

12 Conforme <http://portal.mec.gov.br/programa-mais-educacao/secretarias-e-escolas>. Acesso em: 10 jan. 2016. Vale ressaltar que após o impedimento da Presidenta Dilma Rousseff, o governo que a substituiu lançou o Programa Novo Mais Educação (Portaria n 1.444, de 10/10/2016), cujo foco é a melhorar a aprendizagem de língua portuguesa e matemática no ensino público fundamental.

13 A lei do voluntariado (no 9.608/1998) considera que o serviço voluntário é atividade não remunerada e sem vínculo empregatício, que tenha objetivos cívicos, culturais, educacionais, científicos, recreativos ou de assistência social (art. 1º). O voluntário pode vir a ser ressarcido pelas despesas oriundas do desempenho das atividades (art. $3^{\circ}$ ).

140 prosseguimento dessa pesquisa procurou analisar a gestão do PME na Secretaria Municipal de Educação e em algumas escolas municipais de Duque de Caxias, cidade localizada na Baixada Fluminense, Região Metropolitana do Estado do Rio deJaneiro. Das características positivas sublinhadas pelas diretoras entrevistadas, umas das mais citadas diz respeito ao repasse anual das verbas do PME que em algumas escolas da rede superou os $\mathrm{R} \$ 40.000,00$ (dados de 2013, disponíveis em $<$ https://www.fnde.gov.br/sigap/sistema.pu>. Acesso em: 28 nov. 2015).

15 Para maiores detalhes sobre os primeiros 7 anos de existência do CENPEC, veja o vídeo em que a ONG comemora os seus 20 anos de existência, com depoimentos de educadores que participaram da fundação. Disponível em: <www.cenpec.org. br/app/video/CENPEC20ANOS.flv>. Acesso em: 10 mar. 2015.

\section{Referências}

BRASIL. Lei n. 9.394, de 20 de dezembro de 1996. Estabelece as diretrizes e bases da educação nacional. Diário Oficial da União, Brasília, DF, 23 dez. 1996.

BRASIL. Lei n. 9.608, de 18 de fevereiro de 1998. Dispõe sobre o serviço voluntário. Diário Oficial da União, Brasília, DF, 18 fev. 1998. Disponível em: <http://www. planalto.gov.br/ccivil_03/leis/L9608.htm>. Acesso em: 18 mar. 2015. 
BRASIL. Portaria Interministerial n. 17, de 20 de abril de 2007. Institui o Programa Mais Educação. Diário Oficial da União, Brasília, DF, 24 abr. 2007.

BRASIL. Portaria Interministerial n. 19, de 20 de abril de 2007. Estabelece as diretrizes para a cooperação entre o Ministério da Educação e o Ministério do Esporte, com o objetivo de definir critérios visando a construção de quadras esportiva ou infra-estrutrura esportiva em espaços escolares. Diário Oficial da União, Brasília, DF, 24 abr. 2007.

BRASIL. Decreto n. 6.094, de 24 de abril de 2007. Dispõe sobre a implementação do Plano de Metas Compromisso Todos pela Educação. Diário Oficial da União, Brasília, DF, 24 abr. 2007.Disponível em: <http://www.planalto.gov.br/ccivil_03/_ ato2007-2010/2007/decreto/d6094.htm>. Acesso em: 18 mar. 2015.

BRASIL. Lei n. 11.494, de 20 de junho de 2007. Regulamenta o Fundo de Manutenção e Desenvolvimento da Educação Básica e Valorização dos Profissionais da Educação - FUNDEB. Diário Oficial da União, Brasília, DF, 20 jun. 2007. Disponível em: <http://www.planalto.gov.br/ccivil_03/_ato2007-2010/2007/lei/l11494. htm>. Acesso em 18 mar. 2015.

BRASIL. Ministério da Educação. Educação Integral: texto referência para o debate nacional. Série Mais Educação: Brasília, 2009.

BUTTIGIEG, Joseph. Educação e Hegemonia. In: COUTINHO, Carlos Nelson; TEIXEIRA, Andréa de Paula (Org.). Ler Gramsci, Entender a Realidade. Rio de Janeiro: Civilização Brasileira, 2003. P. 39-50.

CARVALHO, Elma Júlia Gonçalves de. Reestruturação Produtiva, Reforma Administrativa do Estado e Gestão da Educação. Educação e Sociedade, Campinas, v. 30, n. 109, p. 1139-1166, 2007.

CARVALHO, Maria do Carmo Brant de. Educadora, Protetora, Saudável: uma cidade feita de pertencimento. Cadernos CENPEC, São Paulo, n. 1, p. 49-53, 2005.

CARVALHO, Maria do Carmo Brant de. Pensar e Repensar, Fazer e Refazer, Juntos, a Ação Social Pública. Cadernos CENPEC, São Paulo, n. 1, p. 7-14, 2005.

CASTELLS, Manuel. Para o Estado-Rede: globalização econômica e instituições políticas na era da informação. In: PEREIRA, Luís Carlos Bresser; WILHEIM, Jorge; SOLA, Lourdes (Org.). Sociedade e Estado em Transformação. São Paulo: Edunesp, 1999. P. 147-171.

CAVALIERE, Ana Maria. Escolas de Tempo Integral Versus Alunos em Tempo Integral. In: MAURÍCIO, Lúcio Veloso (Org.). Em Aberto: educação integral e tempo integral, Brasília, v. 22, n. 80, p. 51-63, abr. 2009.

CAVALIERE, Ana Maria. Questões sobre uma Proposta Nacional de Gestão Escolar Local. In: CONGRESSO LUSO BRASILEIRO, I CONGRESSO IBERO BRASILEIRO, ESPAÇO PÚBLICO DA EDUCAÇÃO: EMERGÊNCIA DE POLÍTICAS E PRÁTICAS DE GESTÃO LOCAL, REGIONAL E NACIONAL, 4., 2010, Elvas; Cáceres; Mérida. Anais... Elvas; Cáceres; Mérida: 2010. P. 1-11.

CENPEC. Guia de Ações Complementares à Escola para Crianças e Adolescentes. São Paulo: CENPEC, 1994.

CENPEC. Debate: Qual Cidade Educadora Queremos? Cadernos CENPEC, São Paulo, n. 1, p. 15-32, 2005.

CENPEC. CENPEC: uma história e suas histórias. São Paulo: CENPEC; Imprensa do Estado de São Paulo, 2007.

CENPEC. Tendências para Educação Integral. São Paulo: Fundação Itaú Social; CENPEC, 2011.

CENPEC. Percursos da Educação Integral: em busca da qualidade e da equidade. São Paulo: CENPEC; Fundação Itaú Social; Unicef, 2013.

Educação \& Realidade, Porto Alegre, v. 43, n. 2, p. 401-414, abr./jun. 2018. 
Ampliação da Jornada Escolar e o Terceiro Setor

CENPEC; Prêmio Itaú-Unicef. Avaliação de Percurso: fortalecer organizações sociais e induzir políticas de educação integral. São Paulo: CENPEC, 2008.

COELHO, Ligia Martha da Costa. História(s) da Educação Integral. In: MAURÍCIO, Lúcio Velloso (Org.). Em Aberto: educação integral e tempo integral, Brasília, v. 22, n. 80, p. 83-96, abr. 2009.

GARCIA, Joana. O Negócio do Social. Rio de Janeiro: Jorge Zahar Ed., 2004.

GOHN, Maria da Glória. Educação Não Formal e o Educador Social: atuação no desenvolvimento de projetos sociais. São Paulo: Cortez, 2010.

GRAMSCI, Antonio. Cadernos do Cárcere v. 2: os intelectuais. O princípio educativo. Jornalismo. Rio de Janeiro: Civilização Brasileira, 2000a.

GRAMSCI, Antonio. Cadernos do Cárcere v. 3: Maquiavel. Notas sobre o Estado e a política. Rio de Janeiro: Civilização Brasileira, 2000b.

GUARÁ, Isa Maria. Educação, Proteção Social e muitos Espaços para Aprender. In: CENPEC (Org.). Muitos Lugares para Aprender. São Paulo: CENPEC; Fundação Itaú Social; Unicef, 2003, P. 31-45.

GUARÁ, Isa Maria. É Imprescindível Educar Integralmente. Cadernos CENPEC, São Paulo, n. 2, p. 15-24, 2006.

MARTINS, André Silva. A Direita para o Social: a educação da sociabilidade no Brasil contemporâneo. Juiz de Fora: UFJF, 2009.

MARX, Karl; ENGELS, Friedrich. A Ideologia Alemã. São Paulo: Martins Fontes, 1989.

MENEZES, Janaína. Educação Integral \& Tempo Integral na Educação Básica: da LDB ao PDE. In: COELHO, Lígia Martha Coimbra da Costa (Org.). Educação Integral em Tempo Integral: estudos e experiências em processo. Petrópolis, RJ: DP; FAPERJ, 2009. P. 69-88.

MONTAÑO, Carlos. Novas Configurações do Público e do Privado no Contexto Capitalista Atual: o papel político-ideológico do 'terceiro setor'. In: ADRIÃO, Theresa; PERONI, Vera (Org.). Público e Privado na Educação: novos elementos para o debate. São Paulo: Xamã, 2008. P. 27-50.

PERONI, Vera; ADRIÃO, Teresa. Público Não-Estatal: estratégias para o setor educacional brasileiro. In: ADRIÃO, Theresa; PERONI, Vera (Org.). O Público e o Privado na Educação: interface entre Estado e sociedade. São Paulo: Xamã, 2005. P. 137-154.

SAVIANI, Demerval. O Plano de Desenvolvimento da Educação: análise do projeto do MEC. Educação e Sociedade, Campinas, v. 28, n. 100 - Especial, p. 1231-1255, 2007.

SOUZA e SILVA, Maria Alice Setúbal et al. A Escola como Foco de Análise: um estudo de 16 unidades escolares. Cadernos de Pesquisa, São Paulo, n. 95, p. 43-50, nov. 1995.

WORLD BANK. Memorandum of the President of the International Bank for the Reconstruction and Development and the International Finance Corporation to the Executive Directors on a Country Assistance Strategy of the World Bank Group for the Federative Republic of Brazil. Latin America and the Caribbean Regional Office. 12 de junho de 1997. Disponível em:<http://documents.worldbank.org/curated/en/902681468017467876/pdf/multi-page.pdf>. Acesso em: 18 mar. 2015.

Regis Eduardo Coelho Argüelles da Costa é professor do Departamento de Fundamentos Pedagógicos da Faculdade da Educação da Universidade Federal Fluminense (UFF). Doutor em Educação (PPGE/UFRJ) e pesquisador do Núcleo de Estudos - Tempos, Espaços e Educação Integral (NEEPHI/Unirio), e do Laboratório de Investigação em Escola, Poder e Estado (LIEPE/UFRRJ). E-mail: rarguelles@gmail.com

414 Educação \& Realidade, Porto Alegre, v. 43, n. 2, p. 401-414, abr./jun. 2018 